\title{
EDITORIAL
}

\section{KEIKO YASUKAWA}

I begin this editorial by expressing sincere thanks on behalf of the editorial team to a retiring member of the editorial team, Jean Searle. Jean has been a member of the editorial team of Literacy and Numeracy Studies since 2005, and prior to that, she was a member of the Journal's editorial board. She has provided helpful and insightful editorial advice to many of our authors, and has been a strong proponent of our Journal. We have benefited greatly from her editorial expertise as well as her strong involvement as educator and researcher in the field. We wish her the very best in her retirement.

This issue features contributions which, on the surface, are very disparate. Greg Marston and Jeffrey Johnson-Abdelmalik write about a community based adult literacy program in Brisbane, Australia. Sonja Beeli-Zimmermann writes about adult educators learning to become numeracy teachers in a German-speaking town in Switzerland. And in the third article, Tao Bak and Pauline O'Maley write about vocational education and training practitioners assuming responsibilities for the language, literacy and numeracy development of their learners in Melbourne, Australia. A strong common thread in all three articles is the identity work being undertaken - by the adult learners, in the case of the first article, and by teachers in the second and third articles.

The article by Marston and Johnson-Abdelmalik presents accounts of learners in a community-based adult literacy class where the program is built first and foremost around each learner's acknowledged needs and goals. Although notions of 'literacy as empowerment' and social capital as outcomes of participation in learning are not new, the stories in this article illustrate how real and tangible these were in transforming the lives of learners in the program. It is an important piece of research that help us to make the case for more spaces for community based provision of adult literacy and numeracy learning that are not constrained by the too common pre-packaged learning outcomes and performance criteria that can be at odds with the learners' aspirations and needs.

Beeli-Zimmermann's article explores how teachers' beliefs shape their identities as emerging numeracy teachers. Her research adds to existing literature about mathematics teachers' beliefs which are largely

Literacy and Numeracy Studies 2015. (C) 2015 KEIKO YASUKAWA. This is an Open Access article distributed under the terms of the Creative Commons Attribution 4.0 Unported (CC BY 4.0) License (https://creativecommons.org/licenses/by/4.0/), allowing third parties to copy and redistribute the material in any medium or format and to remix, transform, and build upon the material for any purpose, even commercially, provided the original work is properly cited and states its license. 
researched in the school education contexts. For emerging adult numeracy teachers, the beliefs influencing their identities and practices as numeracy teachers are more complex, and include beliefs shaped by their school experiences of mathematics learning as well as their experiences of working as adult educators.

The role of vocational education and training practitioners in addressing their learners' language, literacy and numeracy needs has become a very topical issue in Australia, New Zealand and the United Kingdom. While the idea of literacy and numeracy being critical dimensions of pedagogy may be easy to accept in principle, the idea of taking responsibility for students' literacy and numeracy development may not be so simple in practice for teachers who identify as experts in the electrical trades, or child care, or hospitality. Bak and O'Maley examine the journey of these teachers' learning to expand their understanding of what it means to be a vocational teacher.

Together the three articles contribute to deepening our understanding of how learners and teachers build new identities - in some instances motivated from the start by their own personal needs, in others by external demands and policy changes. 